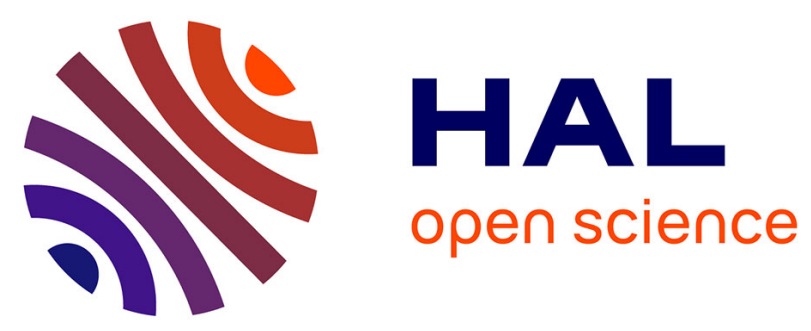

\title{
Assessing the potential risk and relationship between microplastics and phthalates in surface seawater of a heavily human-impacted metropolitan bay in northern China
}

Yandong Liu, Zhaozhao Li, Isabel Jalón-Rojas, Xiao Hua Wang, Erick Fredj, Dahai Zhang, Lijuan Feng, Xianguo Li

\section{To cite this version:}

Yandong Liu, Zhaozhao Li, Isabel Jalón-Rojas, Xiao Hua Wang, Erick Fredj, et al.. Assessing the potential risk and relationship between microplastics and phthalates in surface seawater of a heavily human-impacted metropolitan bay in northern China. Ecotoxicology and Environmental Safety, 2020, 204, pp.111067. 10.1016/j.ecoenv.2020.111067 . hal-03442135

\section{HAL Id: hal-03442135 \\ https://hal.science/hal-03442135}

Submitted on 25 Nov 2021

HAL is a multi-disciplinary open access archive for the deposit and dissemination of scientific research documents, whether they are published or not. The documents may come from teaching and research institutions in France or abroad, or from public or private research centers.
L'archive ouverte pluridisciplinaire HAL, est destinée au dépôt et à la diffusion de documents scientifiques de niveau recherche, publiés ou non, émanant des établissements d'enseignement et de recherche français ou étrangers, des laboratoires publics ou privés. 
1 Assessing the potential risk and relationship between microplastics and phthalates in surface seawater of a heavily human-impacted metropolitan bay in northern China

4

5 Yandong Liu a , Zhaozhao Li a , Isabel Jalón-Rojas ${ }^{\text {b, c }}$, Xiao Hua Wang c, 6 Erick Fredj ${ }^{\mathrm{d}}$, Dahai Zhang ${ }^{\text {a }}$, Lijuan Feng ${ }^{\text {a }}$, Xianguo Li ${ }^{\mathrm{a}^{*}}$ 7

$8{ }^{a}$ Key Laboratory of Marine Chemistry Theory and Technology (Ocean University of China),

9 Ministry of Education, Qingdao 266100, China

10 b UMR5805 EPOC, CNRS, OASU, Université de Bordeaux, Pessac, 33615, France

$11{ }^{\mathrm{c}}$ The Sino-Australian Research Consortium for Coastal Management, School of Science, UNSW

${ }^{\mathrm{d}}$ Jerusalem College of Technology, Jerusalem, Israel

14

15

*Corresponding author:

18

Key Laboratory of Marine Chemistry Theory and Technology (Ocean University of China),

19 Ministry of Education, Qingdao 266100, China

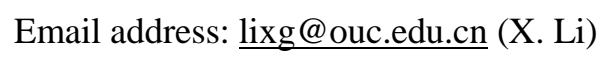


Abstract: The impacts of microplastics (MPs) and phthalates (PAEs), a class of MP-associated contaminants, on the marine environment are not thoroughly understood despite concern over their adverse effects on humans and ecosystems. Field studies linking MPs and PAEs in seawater have not yet been reported. We

27 investigate for the first time the correlation between MPs contamination and the presence of PAEs in the surface seawater of Jiaozhou Bay (JZB), a semi-enclosed metropolitan bay in northern China heavily impacted by human activity. The abundance of MPs, dominated by polyethylene and polyethylene terephthalate mostly

31 smaller than $2 \mathrm{~mm}$, ranged between 24.44 items $/ \mathrm{m}^{3}$ and 180.23 items $/ \mathrm{m}^{3}$, with the majority being black and transparent fibers and fragments. Concentrations of PAEs varied from $129.96 \mathrm{ng} / \mathrm{L}$ to $921.22 \mathrm{ng} / \mathrm{L}$. Relatively higher abundances of MPs and higher concentrations of PAEs were generally found in areas near riverine inputs and sewage treatment plants. There was a strong correlation between PAEs concentration and MPs abundance, suggesting that they are closely linked. In a risk assessment combining PAEs and MPs, the risk quotients (RQs) indicated that the ecological risk of di-n-butyl phthalate in JZB was relatively high $(0.046<\mathrm{RQ}<0.516)$; the risk of the other PAEs were low. The overall ecological hazard index (HI) of PAEs was low to medium $(0.098<\mathrm{HI}<0.897)$. The risk of MPs pollution in $\mathrm{JZB}$, as indicated by

41 Pollution Load Index (PLI), was moderate (PLIJZB=11.76), and mainly due to 42 polyvinyl chloride.

43 Key words: Microplastics; phthalates; risk assessment; surface seawater; Jiaozhou 44 Bay. 


\section{Introduction}

Plastics and their products are widely used because of their convenience, light weight, and other advantageous properties (Andrés et al., 2014). However, the overuse and improper disposal of plastics have caused severe environmental problems (Rochman et al., 2013), because they can persist in the environment for tens to hundreds of years (Thompson et al., 2009). Large quantities of microplastics (MPs, size below $5 \mathrm{~mm}$ ) are released and transported into the ocean through rivers, sewage, and the atmosphere (Barnes et al., 2009). They originate either from intentional manufacturing (such as in facial cleansers, toothpastes, and plastic raw material; primary origin) or subsequent fragmentation of large plastics via mechanical, photochemical, and biological degradation (secondary origin) (Wright et al., 2013). MPs in marine systems are dispersed by waves, tides and ocean currents. They may sink through the water column (Cincinelli et al., 2019) and be incorporated into sediments (Klein et al., 2015; Tsang et al., 2017) or be assimilated by marine organisms (Kang et al., 2015) and hence transferred into the whole food web (Van et al., 2015), including marine mammals (Lusher et al., 2015a).

MPs easily adsorb heavy metals (Wang et al., 2017) and persistent organic pollutants (Guo et al., 2012a; Mai et al., 2018) due to their small particle size and high specific surface area, increasing their potential toxicity. Many harmful additives are also added during the production of plastics, such as plasticizers, flame retardants, and antioxidants (Hermabessiere et al., 2017). When MPs are immersed in seawater, they can release some of these poisonous substances (Hahladakis et al., 2018) and act as 
vectors for pollutant transfer into the marine biota (Zhang et al., 2018a).

Plasticizers are polymer additives used to make plastics flexible, lightweight, and durable. Phthalic acid esters or phthalates (PAEs) have been the most commonly used plasticizers in the plastics industry for decades. PAEs as plasticizers are not chemically bonded with the plastic matrices, and are easily released into the surrounding environment (Dargnat et al., 2009). According to a report by the Information Handling Services (IHS) Chemistry, the amount of PAEs used to produce plasticizers worldwide was nearly 5.9 million tons in 2014 and is expected to rise to about 6.7 million tons by 2019 (Zhang et al., 2018c). Because of the large quantity and widespread application, PAEs are prevalent in the environment, and have been widely found in air, sea, and land environments (Wang et al., 2008; Zhang et al., 2018b). In addition, PAEs have been detected in some aquatic organisms, such as fish (Adeogun et al., 2015) and algae (Babu and $\mathrm{Wu}, 2010$ ). PAEs are endocrine disruptive to animals and humans, and may be mutagenic, teratogenic, and carcinogenic (Guo et al., 2012b). Six PAEs, dimethyl phthalate (DMP), diethyl phthalate (DEP), di-n-butyl phthalate (DBP), butyl benzyl phthalate (BBP), bis(2-Ethylhexyl) phthalate (DEHP), and di-n-octyl phthalate (DnOP), were listed as environmental priority pollutants by the United States Environmental Protection Agency in 2013 (USEPA, 2013).

Jiaozhou Bay (JZB) is a typical semi-enclosed shallow bay in Qingdao, China, which forms a complex and diverse ecosystem with the surrounding land environment (Fu et al., 2007). JZB is also an important fishery and aquatic base, a sea-salt 
89 production base, and a shipping and tourism economic zone in north China (Gao et al.,

90 2003). With the rapid urbanization and industrialization along the JZB coast, large

91 amounts of industrial waste and anthropogenic pollutants are discharged into JZB

92 directly or via several rivers (Shi et al., 2011). The bay has a low water exchange,

93 with an average residence time of 80 days, ranging from less than 20 days in the deep

94 channel up to 120 days in the shallower northwest area (Liu et al., 2004). This long

95 residence time is favorable for the accumulation of pollutants with a high ecological

96 risk. Owing to its special and distinct location and features, JZB has been and

97 continues to be strongly impacted by anthropogenic activities, providing a good

98 system for the study of MPs and related plasticizers.

99

Although Zheng et al. (2019) measured MPs in JZB seawater and sediment

samples, the level of PAEs has not yet been determined, and no study has evaluated

101 the combined risk of MPs and PAEs using observation data. The influence of

102 environmental parameters, such as water level, water temperature, $\mathrm{pH}$, dissolved

103 oxygen, salinity and conductivity, on the distribution and abundance of MPs and

104 PAEs in semi-enclosed metropolitan bays has also not been reported. Therefore, the

105 objectives of this study are: 1) to determine the level of PAEs in JZB surface seawater

106 and the correlation, if any, between MPs and the environmental parameters; 2) to

107 evaluate the ecological risk of MPs and PAEs. This study also provides a preliminary

108 of the chemical additives in plastics that could be used to trace the source of MPs in

109 the environment, and acts as a reference for the study of the environmental effects of

110 and means of reducing MPs. 


\section{Materials and methods}

\subsection{Study area and sample collection}

Located southeast of Shandong Peninsula and west of the Yellow Sea, JZB

city in northern China (Fig. 1). The seawater area of JZB is about $370 \mathrm{~km}^{2}$, with an average water depth of $7 \mathrm{~m}$ (Sun and Sun, 2015). The significant wave height of the bay is generally less than $5 \mathrm{~m}$, with typical semidiurnal tides (Chen et al., 2012).

Several seasonal rivers discharge water, waste, and sediments into the bay including the Dagu, Moshui, Licun, Haibo, and Yang Rivers (Dai et al., 2006; Liang et al.,

121 2015). Several sewage treatment plants are also located on coastline of the bay,

122 including the Tuandao, Haibo, and Licun sewage plants (Fig. 1).

123 MPs samples were collected from surface seawater at 22 sites (Fig. 1) using a

124 seawater intake system on board the R/V Yuan Jian 1 on 22 August, 2018 (Stations 125 A1-A6), 10 September, 2018 (Stations C1-C9) and 2 January, 2019 (Stations D1126 D7). All samples were collected at low tide. Table S1 in the Supplementary 127 Information provides details of the sampling sites and environmental water 128 parameters. An onboard flowmeter was used to measure the volume of pumped water. 129 Typically, $300 \mathrm{~L}$ of seawater was filtered at each collection site using an online 130 system with a $32 \mu \mathrm{m}$ steel sieve (Zhao et al., 2014). The retained particulate material 131 was immediately back-flushed with Milli-Q water (Millipore Co., USA) into a 500 $132 \mathrm{~mL}$ glass bottle and fixed in $2.5 \%$ formalin (Lattin et al., 2004). 
134 clean stainless-steel bucket and placed in clean 4L amber-glass bottles, with roughly 2

$135 \mathrm{~mL}$ of $100 \mathrm{mg} / \mathrm{L}$ sodium azide added to each bottle to inhibit microbial activity (Gong

136 et al., 2019). One field duplicated sample was randomly collected and examined at

137 every three stations to check the representativeness of sampling. The water samples

138 were stored in the dark at $4^{\circ} \mathrm{C}$ and processed as soon as possible. The water

139 temperature (WT), $\mathrm{pH}$, dissolved oxygen (DO), salinity (Sal.) and conductivity (Cond.)

140 were measured in the field using an HQ40d multimeter (Hach, Loveland, CO, USA).

141 The water level (WL) data were read from the sonar system on the ship.

142 2.2. Sample pretreatment and analysis

143 For the MPs measurement, samples were first oxidized to remove organic matter

144 and then filtered. A stereoscopic microscope was used to examine the sample filters

145 for MPs. When these were found, the polymer types were identified with a

146 micro-Fourier transform infrared spectroscope ( $\mu$-FT-IR, PerkinElmer Spectrum

147 Spotlight 400, PerkinElmer, USA). For detailed information about the procedure,

148 readers should refer to the Supplementary Information Section S1.

149 Six USEPA priority PAEs (DMP, DEP, DBP, BBP, DEHP and DnOP) were

150 identified and quantified in our study. Each seawater sample was filtered, the PAEs

151 solid-phase extracted and then quantified with a GC-MS system (Agilent

152 7890A-5975C, Agilent Technologies Inc., California, USA). An internal calibration

153 method was used for quantification. Detailed information can be found in

154 Supplementary Information Section S2. 

chemical components of the MPs (Xu et al., 2018). The risk evaluation of the PAEs

172 was based on the risk quotient (RQ) and potential hazard index (HI) methods,

173 following the guidance from the European Commission (EC, 2003). Detailed 174 descriptions of the assessment methods can be found in Supplementary Information 175 Section S4.

\subsection{Quality assurance $(Q A)$ and quality control $(Q C)$}

Nitrile gloves and cotton lab coats were worn throughout the field work and laboratory experiments. All containers were non-plastic, and were cleaned with Milli-Q water. Blank membrane controls were run in the field and in the laboratory as background checks. Between each sample test, anhydrous ethanol was used to wipe the crystal on the $\mu$-FT-IR to avoid cross-contamination (Zheng et al., 2019).

times with n-hexane before use to prevent any contamination. Detailed procedures and results of the QA/QC for the PAEs analysis, including blanks, spiked-matrix recoveries, duplicated sample analysis, and method detection limit (MDL), are described in Supplementary Information Section S3.

\subsection{Risk assessment related to MPs and PAEs}

Since MPs and PAEs are recent marine pollutants, there is still no systematic and standardized model specifically developed for assessing their potential ecological risk. Therefore, we adopted here the pollution load index (PLI) method (Tomlinson et al., 1980) for the risk assessment of MPs; this is based on both the abundance and the

\subsection{Data analysis}


178 PAEs concentrations were expressed as ng/L. The spatial distributions of the MPs and

179 PAEs were processed using Kriging by Surfer (version 15.0). All statistical analyses

180 were processed using SPSS (version 22.0). Statistical significance was considered at 181 the 0.05 alpha level. The figures were drawn using Origin (version 9.1). Pearson 182 correlation was performed to study the relationships between MPs, PAEs, and 183 environmental water parameters using Matlab.

\section{Results and discussion}

\subsubsection{MPs abundance in surface seawater}

MPs were detected at all sampling stations (Fig. 2a, Table S1), with abundance ranging from 24.44 to 180.23 items $/ \mathrm{m}^{3}$. The mean abundance was $80.46 \pm 44.82$

190 items $/ \mathrm{m}^{3}$ with a median value of 65.34 items $/ \mathrm{m}^{3}$. These values were compared with

191 those found in surface waters in systems around the world, including JZB (Zheng et 192 al., 2019), in order to calibrate the contamination level of MPs in JZB (Fig. 3). This 193 comparison took into account the sampling method used in each study: bulk sampling

194 (used in the present study) or trawling-net sampling. The abundance of MPs observed 195 in this study was very similar to that reported by Zheng et al. (2019) in JZB (20-120 196 items $/ \mathrm{m}^{3}$ ). Of the other studies using the bulk sampling method, a relatively higher 197 abundance was recorded in the Yangtze Estuary, China (1675.8-6598.8 items $/ \mathrm{m}^{3}$, 198 Zhao et al., 2014), in the South China Sea (799-4339 items $/ \mathrm{m}^{3}$, Cai et al., 2018), and 
199 in the Incheon/Kyeonggi coastal region of South Korea (328-2876 items $/ \mathrm{m}^{3}$, Chae et 200 al., 2015). In contrast, significantly lower abundances of MPs were reported in many 201 studies that used trawling-net sampling, for instance the Mediterranean Sea $(0.15$ 202 items $/ \mathrm{m}^{3}$; de Lucia et al., 2014), the Seto Inland Sea (0.39 items $/ \mathrm{m}^{3}$; Isobe et al., 203 2014), and the East China Sea (0.029-0.305 items $/ \mathrm{m}^{3}$; Zhao et al., 2014). In these 204 studies, the lowest abundance of MPs in surface waters was four orders of magnitude 205 lower than the highest for the bulk sampling method. Our results show that MPs were 206 present in the surface seawater of JZB but, compared with other documented systems, 207 the pollution level was still relatively low for a semi-enclosed bay heavily affected by 208 human activity.

209 Spatially, the highest abundance of MPs, 180.23 items $/ \mathrm{m}^{3}$, was found at Station

210 D1 near the Tuandao sewage treatment plant; the lowest abundance, 24.44 items $/ \mathrm{m}^{3}$, 211 was observed at Station D4 near the mouth of the bay. The abundance was therefore 212 up to seven times higher at sites near estuaries and sewage treatment plants than at the 213 other stations in the bay. For example, the MPs abundance at Stations C6 and C7, 214 close to the Lichun River and Haibo River estuaries, ranged from 98.82 to 159.42 215 items $/ \mathrm{m}^{3}$, and the abundance at D1 and C7, close to the Tuandao and Haibo sewage 216 treatment plants, ranged from 159.42 to 180.23 items $/ \mathrm{m}^{3}$. These results suggest that 217 MPs from rivers and sewage treatment plants were the major contributors to MPs in 218 JZB. This agrees with previous studies that found rivers to be one of the major 219 sources of marine MPs pollution (Schmidt et al., 2017), while estuaries are also 220 potential MPs hot spots (Wright et al., 2013). Municipal sewage treatment plants have 
221 long been considered important sources of MPs (Xu et al., 2019). Significant amounts 222 of MPs still enter the environment from these despite the high removal rates of MPs in 223 current sewage treatment (Murphy et al., 2016).

224 The distribution of MPs is not only related to human activity, but also closely 225 related to specific geographical locations (Lusher et al., 2014) and ocean currents. The 226 overall level of MPs in the surface seawater of JZB decreased gradually from east to 227 west. The presence of residual currents, such as the clockwise circulation in the 228 eastern region ( $\mathrm{Li}$ et al., 2014; Yuan et al., 2019), and the low water exchange rate of 229 the bay (Liu et al., 2004) favor the trapping of MPs near the sources. On the other 230 hand, mixing processes combined with strong, flood-dominant tidal currents (Gao et 231 al., 2014) tend to disperse the MPs to different regions of the bay. Clearly, the 232 hydrodynamics plays a significant role in the abundance, distribution, and trapping of 233 MPs. A detailed study of the transport mechanisms that determine the trajectories and 234 distribution patterns of the MPs (e.g. Jalón-Rojas et al, 2019a, b) is a subject of our 235 on-going modelling of JZB.

236 The D-series of samples were collected in a different season to the A- and 237 C-series. Even though seasonal variations have been frequently reported (e.g. 238 Pelamatti et al., 2019), this seems not to be the case in the present study. The MPs 239 abundances were in a similar range at Stations A1-A6 (26.67-133.33 items $/ \mathrm{m}^{3}$, 240 average 66.85 items $\left./ \mathrm{m}^{3}\right), \mathrm{C} 1-\mathrm{C} 9\left(40.00-159.42\right.$ items $/ \mathrm{m}^{3}$, average 88.52 items $\left./ \mathrm{m}^{3}\right)$, 241 and D1-D7 (24.44 -180.23 items $/ \mathrm{m}^{3}$, average 81.77 items $/ \mathrm{m}^{3}$ ) (distribution in Fig. 2, 242 data in Table S1). While significant differences were observed between the different 
243 geographical locations (within the same A, C or D series of samples), the variations

244 between sampling times (between A, C and D series of samples) were relatively 245 small.

\section{3.1.2. MPs characteristics in surface seawater}

247 MPs are generally classified into six categories according to their size: $<0.5 \mathrm{~mm}$,

$2480.5-1 \mathrm{~mm}, 1-2 \mathrm{~mm}, 2-3 \mathrm{~mm}, 3-4 \mathrm{~mm}$, and 4-5 mm. Fig. 4a shows that, except at

249 Station D6, the surface seawater of JZB mainly contained MPs of size less than $2 \mathrm{~mm}$, 250 accounting for up to $71.80 \%$ of the total MPs (see Fig. S1a in Supplementary 251 Information Section). In contrast, MPs with a size of 4-5 mm were the least abundant $252(7.72 \%)$. This dominance of smaller MPs is similar to that in many previous 253 observational studies (e.g. Zhao et al., 2014; Zheng et al., 2019). In general, large 254 plastics are gradually broken up into smaller pieces or particles in the marine 255 environment. As a result, the number of small pieces of plastic increase as the size 256 decreases. The toxicity of MPs particles is related to particle size: the smaller the size, 257 the more toxic they are to marine zooplankton (Jeong et al., 2016).

258 Based on their morphological characteristics, MPs were classified into fibers, 259 fragments, films, and granules. Typical MP samples are shown in Fig.S2 of 260 Supplementary Information Section. Fibers and fragments were the main shapes here, 261 accounting for $75.62 \%$ and $20.82 \%$ of the total MPs, respectively (Fig.S1b in 262 Supplementary Information Section). MPs at Stations A4, A5, C3, and D4 were all 263 fibers (Fig. 4b). Films were detected in five samples, accounting for $1.32 \%$ of the total 264 MPs abundance. Granules were found only in three samples, accounting for $2.24 \%$ of 
the abundance. Microbeads used in personal-care exfoliating products were not detected in this study.

Fishery activities in JZB contributed most to the presence of fibrous MPs, since plastic nets and ropes are the main fishing tools. Urban sewage has long been considered a major source of fibrous plastics, mainly from laundry (Zhao et al., 2015). The high presence of fibers supports the argument in Section 3.1.1 that the relatively high abundance of fiber MPs at the study sites may come, to a large extent, from domestic sewage. Although the use of plastic shopping bags has been restricted, they remain a source of film MPs (Sruthy and Ramasamy, 2017). Plastic granules from raw/unprocessed plastic materials, regarded as primary MPs (Law et al., 2010), were only detected in a few samples in our study area, consistent with previous studies in the East China Sea and Yangtze River Estuary (Zhao et al., 2014).

Colored MPs are more likely to be ingested by organisms, as they are more similar to their prey (Abayomi et al., 2017; Wang et al., 2017). Different colors of MPs were observed in the samples, including black, white, transparent, and colored ones. Black was the dominant color found in our study area (Fig. 4c), accounting for $51.17 \%$ of the total MPs (Fig. S1c), followed by colored MPs, including red, blue and green, accounting for $3.30 \sim 31.51 \%$ of the MPs. Transparent and white MPs, accounting for $12.45 \%$ and $4.87 \%$, respectively, were also observed. These observations are consistent with a previous study by Zheng et al. (2019) that also observed large number of black fibers.

The color of MPs is usually derived from their original plastic products, but it 
287 can also be changed because of photodegradation and other processes. Consequently, 288 residence times of MPs in the water may be a controlling factor in the degree of color 289 alteration. For example, some blue and green lines might lose most of their original 290 colors and appear white (Zhang et al., 2017). In our study area, white MPs had a 291 relatively higher abundance at Stations C6 (19\%) and C7 (17\%), which are close to 292 the estuaries of the Licun and Haibo Rivers and municipal sewage treatment plants 293 (Fig. 1). The waste-water treatment processes and the potential weathering undergone 294 during the transport by rivers probably had a bleaching effect on the MPs, resulting in 295 an increased proportion of lightly colored MPs in the effluent. Xu et al. (2019) also 296 found that the abundance of light-colored MPs (white, transparent, yellow, 297 yellow-brown) accounted for the highest proportion in sewage waters $(58.54 \%$ and $29865.38 \%$ in the influent and effluent, respectively). White or lightly colored MPs (e.g. 299 discolored yellow, transparent) usually form a higher proportion in surface water 300 (Campanale et al., 2020) due to their higher mass production and their subsequent 301 improper disposal (Wang et al., 2020). Eight different polymer types were identified in the surface seawater samples 303 (Fig. 4d and Fig. S1d), including polyethylene (PE, accounting for $46.71 \%$ of the total 304 abundance), polyethylene terephthalate (PET, 26.86\%), rayon (14.80\%), 305 polypropylene (PP, 3.66\%), polyvinyl chloride (PVC, 3.35\%), polyamide (PA, $3062.60 \%$ ), polystyrene (PS, 1.09\%), and polyester (0.92\%). PE, PET, rayon, PP, and 307 PVC were the dominant types of MPs (Fig. 5), with PE and PP were the most widely 308 used in our daily life and industry (Klein et al., 2015), such as food packaging and 
water pipeline. PE (with a density of $\left.0.86-0.96 \mathrm{~g} / \mathrm{cm}^{3}\right)$ and PP $\left(0.85-0.91 \mathrm{~g} / \mathrm{cm}^{3}\right)$ are readily transported by surface currents because of their lower specific densities

311 compared to seawater (Jalón-Rojas et al., 2019a; Zheng et al., 2019). The fate of these

312 MPs depends on biofouling or biological metabolism processes (Katija et al., 2017)

313 which increase their density, causing their ultimate deposition onto the seafloor 314 (Jalón-Rojas et al., 2019a).

315 3.2.PAEs

\subsubsection{Concentration of PAEs in surface seawater}

317 Fig. $2 \mathrm{~b}$ and Table $\mathrm{S} 1$ summarize the PAEs concentrations in the JZB surface 318 seawater at each site. All the PAEs, except DnOP, were detected in all samples (Table 319 1), with detection frequencies ranging from 41.38 to $100.00 \%$. The concentrations of $320 \Sigma_{6}$ PAEs (sum of the concentrations of the six PAEs) ranged from 129.96 to 921.22 $321 \mathrm{ng} / \mathrm{L}$, with an average of $342.01 \mathrm{ng} / \mathrm{L}$. The concentration of DEHP was lower than the 322 values reported for the Yellow River and Yangtze River in China (Sha et al., 2007;

323 Wang et al., 2008), but significantly higher than that detected in the Tama River in 324 Japan (Suzuki et al., 2001). In addition, DBP and DEHP were found to be much more 325 abundant than any other four congeners (DMP, DEP, BBP and DnOP), with 326 concentrations varying from < MDL to $248.03 \mathrm{ng} / \mathrm{L}$ (averaged at $158.09 \mathrm{ng} / \mathrm{L}$, 327 accounting for $46.22 \%$ of $\Sigma_{6}$ PAEs) and 60.42 to $617.18 \mathrm{ng} / \mathrm{L}$ (averaged at 140.31 $328 \mathrm{ng} / \mathrm{L}, 41.02 \%$ of $\left.\Sigma_{6} \mathrm{PAEs}\right)$, respectively. This is consistent with environmental water 329 samples from nine rivers and two seas in seven areas in China (Wu et al., 2013). DBP 330 is widely used in cosmetics (Giulivo et al., 2016), and the DEHP came mainly from 
331 plastics and the chemical industry (Simoneit et al., 2005). DBP and DEHP are also 332 major PAEs in household garbage (in toys, plastic packaging materials, etc) (Gao and

333 Wen, 2016). In summary, PAEs in JZB surface water mainly come from plastics, the 334 chemical industry and household waste.

335 It is well documented that the octanol-water partitioning coefficient $\left(\lg K_{\text {ow }}\right)$ of a 336 PAE is closely related to its alkyl chain length: the longer the alkyl chain, the greater 337 the octanol-water partitioning coefficient (as summarized in Table S2), which was 338 proven by many previous studies including a recent correlation analysis (Li et al., 339 2020). In turn, the greater the octanol-water partitioning coefficient, the higher the 340 lipophilicity (or fat-solubility) of PAEs, and the more difficult the degradation of 341 PAEs by photolysis, hydrolysis, and biological processes (Gao and Wen, 2016). 342 Therefore, it is not a surprise that the concentrations of DBP and DEHP (with 343 relatively longer alkyl chains) in seawater are higher than those of the other PAEs. In 344 addition, the higher the lipophilicity, the greater the threat to aquatic organisms 345 (Dordio et al., 2011).

346 Legislation in China is continuously refining the standards for various pollutants 347 in a wide range of wastes. However, MPs and PAEs discharge limits are not included 348 in the current national standard for sewage discharge implemented by the Ministry of 349 Environmental Protection of China (MEP, 2002a, b). In addition, there are still great 350 challenges for removing organic pollutants in domestic sewage water, with 351 biodegradation a key step. Technologies are still under development, which may be 352 greatly benefited from identification of highly efficient degradation bacteria and 
microbial communities. At most $18 \%$ of PAEs are removed by the current treatment

354 equipment in sewage plants (Zhang et al., 2018b). Even if the sewage plants ensured

355 strict observance of standards, the discharge of treated water would be still a 356 significant source of PAEs.

357 Compared with other rivers, lakes, and oceans (Dargnat et al., 2009; Zhang et al.,

$3582018 b, c)$, the current PAEs concentration in JZB surface water is moderate to slightly

359 low. However, with the rapid development of the marine economic zone along the 360 coast of the Shandong Peninsula, pollution in JZB, including MPs and PAEs (and 361 many other organic pollutants), is increasing markedly.

\section{3.2.2. Spatial distribution of PAEs}

363 The total PAEs concentrations in the east JZB, at Stations C6, C7, and D7 near 364 the mouth of the Licun and Haibo Rivers, and at Stations D1and C7 near the Tuandao 365 and Haibo sewage treatment plants, were all relatively high (Fig. 2b, S3). The total 366 PAEs concentration at Station D1 was as high as $921.22 \mathrm{ng} / \mathrm{L}$. As for PAE congeners, 367 the spatial variation trend of DBP and DEHP were similar to that of $\sum_{6}$ PAEs in 368 seawater. This is not a surprise, since DBP and DEHP were the major components 369 accounting for $87.24 \%$ of $\sum{ }_{6}$ PAEs, as presented in Section 3.2.1.

370 In general, the PAEs concentrations at nearshore stations were higher than those

371 in the middle of the bay, and the eastern-shore concentration higher than the 372 western-shore. The higher concentrations of PAEs in the east probably come from 373 surface runoff into JZB, with industries in Qingdao mainly located on the east coast. 374 The Licun, Haibo, and several other rivers east of Qingdao are heavily polluted, with 
very low flows, carrying a large amount of organic pollutants from various sources in

376 the city into JZB. Several sewage plants, such as the Tuandao and Haibo sewage

377 treatment plants, also discharge effluent directly into JZB. Many mariculture farms

378 located in the northeastern waters close to the city also contributed to the high levels

379 of PAEs in the region (Ting et al., 2017).

380 The seasonal variation in PAEs concentrations, reported in previous studies (e.g.

381 Zeng et al., 2009), were much less than the variations between different sampling 382 stations, similar to the case for MPs abundance discussed in Section 3.1.1. The PAEs' 383 concentration ranges and mean values were of the same order of magnitude for 384 Stations A1-A6 (188.51-391.62 ng/L, average $284.61 \mathrm{ng} / \mathrm{L}), \mathrm{C} 1-\mathrm{C} 9$ (235.73-507.14 $385 \mathrm{ng} / \mathrm{L}$, average $347.54 \mathrm{ng} / \mathrm{L})$ and D1-D7 (129.96-921.22 ng/L, average $384.10 \mathrm{ng} / \mathrm{L})$.

386 3.3.Correlations between MPs, PAEs and environmental parameters.

387 As PAEs are used for plastics production, we investigated the correlation 388 between the MPs abundance $\left(\right.$ items $\left./ \mathrm{m}^{3}\right)$ and PAEs concentrations $\left(\Sigma_{6} \mathrm{PAEs}, \mathrm{ng} / \mathrm{L}\right)$ in 389 JZB surface seawater to explore the possible relationship between the two pollutants. 390 A significantly positive correlation was found $\left(r^{2}=0.745, p<0.01, n=22\right.$; Fig. 6$)$.

391 As discussed in Section 3.2, MPs and PAEs are correlated each other, both of 392 which are the result of human activity. After they enter the marine system via either 393 atmospheric deposition, surface runoff or riverine input, MPs are prone both to the 394 adsorbing of waterborne contaminants and to the leaching of their plasticizers 395 (Koelmans et al., 2016), leading to the strong correlation between MPs and PAEs 396 found in JZB seawater. The adsorption of waterborne contaminants by MPs and the 
release of additives are concurrent processes, and their relative contributions to PAEs

398 levels are still a question to be resolved. It might be helpful to combine field studies

399 with numerical simulations to establish the relationship between contaminant

400 concentration and MPs abundance in specific samples, as well as to investigate the 401 spread through the food chain of these contaminants.

402 Previous studies also found relationships between PAEs and MPs in a variety of 403 cases. Baini et al. (2017) found correlations between four PAEs and MPs in neustonic 404 samples from the northwestern Mediterranean Sea. Fossi et al. (2016) reported that 405 PAEs were used as indirect (adsorbed contaminants) and plastic (component 406 contaminants) tracers for MPs in the baleen-whale food chain. The present study 407 reports their relationship in seawater samples, which further confirms that the 408 migration behavior of organic pollutants, such as PAEs, is a possible indirect method 409 to trace the source of MPs in the environment.

411 water parameters (Fig. S4). Water level (WL) was significantly negatively correlated 412 with MPs and PAEs $(r=-0.532, p<0.05 ; r=-0.512, p<0.05$, respectively). This 413 suggests that WL is an important environmental factor in the distribution of MPs and 414 PAEs. It could be that shallower waters are characterized by shorter residence times 415 and slower currents, but the transport mechanisms of MPs in JZB need to be 416 investigated in depth. It is interesting to note that $\mathrm{pH}, \mathrm{DO}$, Sal., and Cond. are strongly 417 associated with WT $\left(5.4-28.2^{\circ} \mathrm{C}\right)$, which is related to sampling time or season. 418 However, there was no clear correlation between these parameters and MPs 
abundance, neither with PAEs concentration.

\subsection{Assessment of ecological risk}

\subsubsection{MPs risk assessment}

The MPs polymer risk index $\mathrm{H}$ in JZB surface water varied from I to IV, with an uneven distribution (Fig. 2C). These high values were mainly due to the presence of high-risky polymers such as PVC, one of the most widely used plastics (Ye et al., 2017). Once PVC enters the marine environment, it can release carcinogenic monomers and other pollutants, impacting the wildlife (Green et al., 2016). Unreacted monomers and polymeric impurities in plastic products can also be released into the environment, threatening human health and ecosystem health (Araújo et al., 2002).

The MPs pollution load in JZB based on the Pollution Load Index (PLI) is given in Fig. 2d. Fifteen sites were moderately polluted, the other seven mildly polluted. According to this result, the MPs pollution risk in JZB surface seawater is not dramatic. The whole area is characterized by a medium level of pollution risk (Fig. 2c, d) with a PLIJzB value of 11.76 , which falls into risk category II .

\subsubsection{Potential ecological risk related to PAEs}

We assessed the ecological risk of the four main PAEs in JZB surface seawater. The risk quotient (RQ) of DMP, DEP, and DEHP were lower than 0.1 at the 22 sampling stations, except at Stations C7, C8, D1 and D7, indicating an overall low ecological risk. Relative higher RQs were found for DBP $(0.1<\mathrm{RQ}<1$, except at Stations D4 and D7; Fig. S5), which indicates that DBP is a medium ecological risk. These results demonstrate that PAEs are becoming a potential threat to the ecology of 
JZB, which deserves further study.

The hazard index (HI) values, ranging between 0.098 and 0.897 , indicate medium-to-low ecological risk in JZB surface seawater. The HI value at Station D1 (0.897) was significantly higher than elsewhere, indicating that areas near sewage treatment plants are generally at a higher level of ecological risk. Higher HI levels were also observed at Station C6 (0.572) and C7 (0.588), which may be related to riverine input.

The risk assessment presented here has some limitations. For instance, it is difficult to determine the PNEC (Predicted No Effect Concentration) for each PAE congener because the environmental toxicology and ecotoxicological information on these pollutants are very limited. Further assessment of the ecological risks of these emerging pollutants is needed to provide more toxicity data (Gong et al., 2019).

\section{Conclusions}

The present study offers novel insights into the occurrence, distribution, correlation, and potential ecological risks of microplastics (MPs) and phthalates (PAEs) in surface seawater of a semi-enclosed bay heavily impacted by human activity, Jiaozhou Bay (JZB) in northern China.

The abundance of MPs in the bay was relatively low compared to other similar areas. The MP and PAE pollution was relatively severe near the estuaries and sewage plants, suggesting that rivers and sewage plants were the main sources of MPs and PAEs. A strong correlation between the abundance of MPs and concentration of PAEs 
was observed in surface seawater.

The ecological risk assessment of PAEs, based on risk quotients, indicated that PAEs, presently at low-to-medium level, are becoming a potential threat to the JZB ecosystem. The risk-assessment model, based on MPs concentrations and polymer chemical hazards showed a high risk related to the presence of hazardous polymers such as PVC. The risk of MPs pollution in the bay was evaluated as medium.

Further studies on the impact of MPs on the transport of organic pollutants in marine environment are important in providing basic data for a source-to-sink study on pollutants in the ocean and a theoretical basis for the control of MPs pollution, as is more comprehensive modeling to help understand MP transport dynamics in a highly urbanized estuarine environment such as JZB.

\section{Acknowledgments}

This work was financially supported by the Fundamental Research Funds for the Central Universities in the Ocean University of China (No. 201861015) and a JZB scoping grant from Sino-Australian Research Centre for Coastal Management at UNSW Canberra. The $\mu$-FT-IR test was carried out by the research team of Professor Chengjun Sun and the GC-MS detection by Dr. Bin Han and Professor Li Zheng (all at the Ecological Center of the First Institute of Oceanography, Ministry of Natural Resources, China), to whom we owe our great thanks. Our thanks also goes to Dr. Peter McInyre of..... for his help in English editing. This is publication No. 76 of the Sino-Australian Research Consortium for Coastal Management at UNSW Canberra, 
References

488

Abayomi, O.A., Range, P., Al-Ghouti, M.A., Obbard, J.P., Almeer, S.H., Ben-Hamadou, R., 2017. Microplastics in coastal environments of the Arabian Gulf. Mar. Pollut. Bull. 124 (1), 181-188.

Adeogun, A.O., Ibor, O.R., Omogbemi, E.D., Chukwuka, A.V., Adegbola, R.A., Adewuyi, G.A., Arukwe, A., 2015. Environmental occurrence and biota concentration of phthalate esters in Epe and Lagos Lagoons, Nigeria. Mar. Environ. Res. 108, 24-32.

Andrés, C., Fidel, E., J Ignacio, et al., 2014. Plastic debris in the open ocean. Proc. Natl. Acad. Sci. U. S. A. 111 (28), 10239-10244.

Araújo, P.H.H., Sayer, C., Poco, J.G.R., Giudici, R., 2002. Techniques for reducing residual monomer content in polymers: a review. Polym. Eng. Sci. 42, 1442-1468.

Babu, B., Wu, J.T., 2010. Production of phthalate esters by nuisance freshwater algae and cyanobacteria. Sci. Total Environ. 408, 4969-4975.

Bagaev, A., Khatmullina, L., Chubarenko, I., 2018. Anthropogenic microlitter in the Baltic Sea water column. Mar. Pollut. Bull. 129 (2), 918-923.

Baini, M., Martellini, T., Cincinelli, A., Campani, T., Minutoli, R., Panti, C., Finoia, M.G., Fossi, M.C., 2017. First detection of seven phthalate esters (PAEs) as plastic tracers in superficial neustonic/planktonic samples and cetacean blubber. Anal. Methods. 9 (9), 1512-1520.

Barnes, D. K. A.; Galgani, F.; Thompson, R. C.; Barlaz, M., 2009. Accumulation and fragmentation of plastic debris in global environments. Philos. Trans. R. Soc. B, 364 (1526), 
1985-1998.

508 Cai, M., He, H., Liu, M., Li, S., Tang, G., Wang, W., Huang, P., Wei, G., Lin, Y., Chen, B., Hu, J., Cen, Z., 2018. Lost but can't be neglected: Huge quantities of small microplastics hide in the South China Sea. Sci. Total Environ. 633, 1206-1216.

511 Campanale, C., Stock, F., Massarelli, C., Kochleus, C., Bagnuolo, G., Reifferscheid, G., Uricchio, V. F., 2020. Microplastics and their possible sources: The example of Ofanto River in southeast Italy. Environ. Pollut. 258, 113284.

514 Chae, D.H., Kim, I.S., Kim, S.K., Song, Y.K., Shim, W.J., 2015. Abundance and distribution characteristics of microplastics in surface seawaters of the Incheon/Kyeonggi Coastal Region. Arch. Environ. Contam. Toxicol. 69 (3), 269-278.

517 Chen, B., Zhang, Y., Liu, J., Kong, X., 2012. Tidal current dynamic characteristic and its relation with suspended sediment concentration in Jiaozhou Bay. Adv. Mar. Sci. 30 (1), 24-35 (in Chinese).

Chen, M., Jin, M., Tao, P., Wang, Z., Xie, W., Yu, X., Wang, K., 2018. Assessment of microplastics derived from mariculture in Xiangshan Bay, China. Environ. Pollut. 242,

Cheung, P.K., Fok, L., Hung, P.L., Cheung, L.T.O., 2018. Spatio-temporal comparison of neustonic microplastic density in Hong Kong waters under the influence of the Pearl River Estuary. Sci. Total Environ. 628-629, 731-739.

526 Cincinelli, A., Martellini, T., Guerranti, C., Scopetani, C., Chelazzi, D., Giarrizzo, T., 2019. A potpourri of microplastics in the sea surface and water column of the Mediterranean Sea. Trends Anal. Chem. 110, 321-326. 
Dai, J.C., Song, J.M., Zheng, G.X., 2006. Analysis of sedimentary environmental evolution of the Jiaozhou Bay. Adv. Mar. Sci. 24 (3), 397-406 (in Chinese).

531 Dargnat, C., Blanchard, M., Chevreuil, M., Teil, M.J., 2009. Occurrence of phthalate esters in the Seine River estuary (France). Hydrol. Process. 23, 1192-1201.

de Lucia, G.A., Caliani, I., et al., 2014. Amount and distribution of neustonic micro-plastic off the western Sardinian coast (Central-Western Mediterranean Sea). Mar. Environ. Res. 100, $10-16$.

Desforges, J. W., Galbraith, M., Dangerfield, N., Ross, P. S., 2014. Widespread distribution of microplastics in subsurface seawater in the NE Pacific Ocean. Mar. Pollut. Bull. 79(1), 94-99.

Dordio, A. V., Belo, M., Teixeira, D. M., Carvalho, A. P., Dias, C. M. B., Picó, Y., Pinto, A. P., 2011. Evaluation of carbamazepine uptake and metabolization by Typha spp., a plant with

EC, 2003. European Commission Technical Guidance Document in Support of Commission Directive 93/67/EEC on Risk Assessment for New Notified Substances and Commission Regulation (EC) No 1488/94 on Risk Assessment for Existing Substance, Part II. Brussels,

Fossi, M. C., Marsili, L., Baini, M., et al., 2016. Fin whales and microplastics: The Mediterranean Sea and the Sea of Cortez scenarios. Environ. Pollut. 209, 68-78.

547 Fu, M., Li, Z., Gao, H., 2007. Distribution characteristics of nonylphenol in Jiaozhou Bay of 548 Qingdao and its adjacent rivers. Chemosphere. 69 (7), 1009-1016.

549 Gao, D. W., Wen, Z. D., 2016. Phthalate esters in the environment: A critical review of their occurrence, biodegradation, and removal during wastewater treatment processes. Sci. Total 
552 Gao, G. D., Wang, X. H., Bao, X. W., 2014. Land reclamation and its impact on tidal dynamics in Jiaozhou Bay, Qingdao, China. Estuar. Coast. Shelf Sci. 151, 285-294.

554 Gao, S.Q., Lin, Y.A., Jin, M.M., 2003. Transport and distribution of nutrients in anchovy spawning ground to the southern waters of Shandong Peninsula. Acta Oceanol. Sin. 4, 533-546.

557

Giulivo, M., de Alda, M. L., Capri, E., Barceló, D., 2016. Human exposure to endocrine disrupting compounds: Their role in reproductive systems, metabolic syndrome and breast cancer. A review. Environ. Res. 151, 251-264.

Gong, J., Lin, C., Xiong, X., Chen, D., Chen, Y., Zhou, Y., Wu, C., Du, Y., 2019. Occurrence, distribution, and potential risks of environmental corticosteroids in surface waters from the Pearl River Delta, South China. Environ. Pollut. 251, 102-109.

Green, D.S., Boots, B., Sigwart, J., Jiang, S., Rocha, C., 2016. Effects of conventional and biodegradable microplastics on a marine ecosystem engineer (Arenicola marina) and sediment nutrient cycling. Environ. Pollut. 208, 426-434.

Guo, X.Y., Wang, X.L., Zhou, X.Z., Kong, X.Z., Tao, S., Xing, B.S., 2012a. Sorption of four hydrophobic organic compounds by three chemically distinct polymers: role of chemical and physical composition. Environ. Sci. Technol. 46 (13), 7252-7259.

Guo, Y., Zhang, Z., Liu, L., Li, Y., Ren, N., Kannan, K., 2012b. Occurrence and profiles of phthalates in foodstuffs from China and their implications for human exposure. J. Agric. Food Chem. 60 (27), 6913-6919.

Hahladakis, J.N., Velis, C.A., Weber, R., Iacovidou, E., Purnell, P., 2018. An overview of 

during their use, disposal and recycling. J. Hazard. Mater. 344, 179-199.

575 Hermabessiere, L., Dehaut, A., Paul-Pont, I., Lacroix, C., Jezequel, R., Soudant, P., Dufols, G., 2017. Occurrence and effects of plastic additives on marine environments and organisms: a review. Chemosphere. 182, 781-793.

Isobe, A., Kubo, K., Tamura, Y., Kako, S., Nakashima, E., Fujii, N., 2014. Selective transport of microplastics and mesoplastics by drifting in coastal waters. Mar. Pollut. Bull. 89 (1-2), 324-330.

Isobe, A., Uchida, K., Tadashi, T., Lwasaki, S., 2015. East Asian seas: A hot spot of pelagic microplastics. Mar. Pollut. Bull. 101 (2), 618-623.

Jalón-Rojas, I., Wang, X. H., Fredj, E., 2019a. On the importance of a three-dimensional approach for modelling the transport of neustic microplastics. Ocean Science, 15(3), 717-724. debris (TrackMPD): sensitivity of microplastic trajectories and fates to particle dynamical properties and physical processes. Mar. Pollut. Bull. 141, 256-272. Lee, S.J., Lee, J.S., 2016. Microplastic size-dependent toxicity, oxidative stress induction, and p-JNK and p-p38 activation in the monogonont rotifer (Brachionus koreanus). Environ. Sci. Technol. 50 (16), 8849-8857. 

the seafloor: how giant larvaceans transport microplastics into the deep sea. Sci. Adv. 3, e1700715.

Klein, S., Worch, E., Knepper, T.P., 2015. Occurrence and spatial distribution of microplastics in river shore sediments of the Rhine-Main area in Germany. Environ. Sci. Technol. 49, 6070-6076.

601 Koelmans, A. A., Bakir, A., Burton, G. A., Janssen, C. R., 2016. Microplastic as a vector for chemicals in the aquatic environment: critical review and model-supported reinterpretation of empirical studies. Environ. Sci. Technol. 50 (7), 3315-3326.

604

Lattin, G.L., Moore, C.J., Zellers, A.F., Moore, S.L., Weisberg, S.B., 2004. A comparison of neustonic plastic and zooplankton at different depths near the Southern California shore. Mar. Pollut. Bull. 49 (4), 291-294.

607

Law, K.L., Morét-Ferguson, S., Maximenko, N.A., Proskurowski, G., Peacock, E.E., Hafner, J., Reddy, C.M., 2010. Plastic accumulation in the North Atlantic subtropical gyre. Science. 329 (5996), 1185-1188.

Liang, S.K., Pearson, S., Wu, W., Ma, Y.J., Qiao, L.L., Wang, X.H., Li, J.M., Wang, X.L., 2015. Research and integrated coastal zone management in rapidly developing estuarine harbours: a review to inform sustainment of functions in Jiaozhou Bay, China. Ocean Coast. Manag. 116, 470-477. 
Li, Y., Yan, H., Liu, Q., Li, X., Ge, J., Yu, X., 2020. Accumulation and transport patterns of six phthalic acid esters (PAEs) in two leafy vegetables under hydroponic conditions. Chemosphere. 249, 126457.

Liu, Z., Wei, H., Liu, G.S., Zhang, J., 2004. Simulation of water exchange in Jiaozhou Bay by average residence time approach. Estuar. Coast. Shelf Sci. 61 (1), 25-35.

Lusher, A.L., Burke, A., O'Connor, I., Officer, R., 2014. Microplastic pollution in the Northeast Atlantic Ocean: validated and opportunistic sampling. Mar. Pollut. Bull. 88 (1-2), 325-333.

Lusher, A. L.; Hernandez-Milian, G.; O’Brien, J.; Berrow, S.; O’Connor, I.; Officer, R., 2015a. Microplastic and macroplastic ingestion by a deep diving, oceanic cetacean: the True's beaked whale Mesoplodon mirus. Environ. Pollut. 199, 185-191.

Lusher, A.L., Tirelli, V., O'Connor, I., Officer, R., 2015b. Microplastics in Arctic polar waters: the first reported values of particles in surface and sub-surface samples. Sci. Rep. 5, 14947.

Mai, L., Bao, L.J., Shi, L., Liu, L.Y., Zeng, E.Y., 2018. Polycyclic aromatic hydrocarbons affiliated with microplastics in surface waters of Bohai and Huanghai Seas, China. Environ. Pollut. 241, 834-840.

MEP, 2002a. Discharge Standard of Pollutants for Municipal Wastewater Treatment Plant (GB18918-2002). China Environment Press, Beijing.

MEP, 2002b. Surface Water Quantity Standards (GB8938-2002). China Environment Press, Beijing.

Murphy, F., Ewins, C., Carbonnier, F., Quinn, B., 2016. Wastewater treatment works (WwTW) as a source of microplastics in the aquatic environment. Environ. Sci. Technol. 50 (11), 5800-5808. 
Pelamatti, T., Fonseca-Ponce, I. A., Rios-Mendoza, L. M., Stewart, J. D., Marin-Enriquez, E., Marmolejo-Rodriguez, A. J., Hoyos-Padilla, E. M., Galvan-Magana, F. G., Gonzalez-Armas, R., 2019. Seasonal variation in the abundance of marine plastic debris in Banderas Bay,

Rochman, C.M., Browne, M.A., Halpern, B.S., Hentschel, B.T., Hoh, E., Karapanagioti, H.K., Rios-Mendoza, L.M., Takada, H., Teh, S., Thompson, R.C., 2013. Policy: Classify plastic waste as hazardous. Nature. 494 (7436), 169-171.

646 Schmidt, C., Krauth, T., Wagner, S., 2017. Export of plastic debris by rivers into the sea. Environ. Sci. Technol. 51(21), 12246-12253.

648 Sha, Y., Xia, X., Yang, Z., Huang, G.H., 2007. Distribution of PAEs in the middle and lower reaches of the Yellow River, China. Environ. Monit. Assess. 124, 277-287.

Shi, J., Li, G., Wang, P., 2011. Anthropogenic influences on the tidal prism and water exchanges in Jiaozhou Bay, Qingdao, China. J. Coast. Res. 27(1), 57-72.

652

Simoneit, B. R., Medeiros, P. M., Didyk, B. M., 2005. Combustion products of plastics as indicators for refuse burning in the atmosphere. Environ. Sci. Technol. 39 (18), 6961-6970.

654 Sruthy, S., Ramasamy, E.V., 2017. Microplastic pollution in Vembanad Lake, Kerala, India: the first report of microplastics in lake and estuarine sediments in India. Environ. Pollut. 222, 315-322.

Sun, S., Sun, X.X., 2015. The Theory and Practice of Gulf Ecosystem-A Case Study for Jiaozhou Bay. Science Press, Beijing, pp. 12-235 (in Chinese). river water by solid-phase extraction and GC-MS determination. Environ. Sci. Technol. 35, 
662 Thompson, R.C., Moore, C.J., Vom Saal, F.S., Swan, S.H., 2009. Plastics, the environment and human health: current consensus and future trends. Philos. Trans. R. Soc. B. 364 (1526), 2153-2166.

Ting, J. U., Wei, G. E., Chao, C. H. A. I., 2017. Pollution and ecological risk assessment of polybrominated diphenyl ethers in the sediments of Jiaozhou Bay. Environ. Chem. (China). 36 (4): 839-848. heavy-metal levels in estuaries and the formation of a pollution index. Helgoländer Meeresun. $33,566-575$.

671 Tsang, Y. Y., Mak, C. W., Liebich, C., Lam, S. W., Sze, E. T., Chan, K. M., 2017. Microplastic pollution in the marine waters and sediments of Hong Kong. Mar. Pollut. Bull. 115 (1-2), 20-28.

USEPA, 2013. Electronic Code of Federal Regulations, Title 40-Protection of Environment, Part 423d Steam Electric Power Generating Point Source Category. Appendix A to Part 423-126, Priority Pollutants. are taken up by mussels (Mytilus edulis) and lugworms (Arenicolamarina) living in natural habitats. Environ. Pollut. 199, 10-17. 
683

684

685

686

687

688

689

Wang, J., Peng, J., Tan, Z., Gao, Y., Zhan, Z., Chen, Q., Cai, L., 2017. Microplastics in the surface sediments from the Beijiang River littoral zone: composition, abundance, surface textures and interaction with heavy metals. Chemosphere 171, 248-258.

Wang, P., Wang, S.L., Fan, C.Q., 2008. Atmospheric distribution of particulate- and gasphase phthalic esters (PAEs) in a Metropolitan City, Nanjing, East China. Chemosphere. 72, $1567-1572$.

Wright, S.L., Thompson, R.C., Galloway, T.S., 2013. The physical impacts of microplastics on marine organisms: a review. Environ. Pollut. 178, 483-492.

Wu, X.L., Hong, H.J., Liu, X.T., Guan, W.B., Meng, L.X., Ye, Y., Ma, Y.Q., 2013. Graphene dispersive solid-phase extraction of phthalate acid esters from environmental water. Sci. Total Environ. 444, 224-230.

Xu, P., Peng, G., Su, L., Gao, Y., Gao, L., Li, D., 2018. Microplastic risk assessment in surface waters: a case study in the Changjiang Estuary, China. Mar. Pollut. Bull., 133, 647-654.

Xu, X., Jian, Y., Xue, Y., Hou, Q., Wang, L., 2019. Microplastics in the wastewater treatment plants (WWTPs): Occurrence and removal. Chemosphere. 235, 1089-1096.

Ye, L., Qi, C., Hong, J., Ma, X., 2017. Life cycle assessment of polyvinyl chloride production and its recyclability in China. J. Clean. Prod. 142, 2965-2972.

Yuan, Y., Jalón-Rojas, I., Wang, X. H., Song, D., 2019. Design, construction, and application of a regional ocean database: A case study in Jiaozhou Bay, China. Limnology and Oceanography: Methods, 17(3), 210-222.

Zeng, F., Wen, J., Cui, K., Wu, L., Liu, M., Li, Y., Lin, Y., Zhu, F., Ma, Z., Zeng, Z., 2009. Seasonal distribution of phthalate esters in surface water of the urban lakes in the subtropical 
Zhang, H., Zhou, Q., Xie, Z., Zhou, Y., Tu, C., Fu, C., Mi, W., Ebinghaus, R., Christie, P., Luo, Y., 2018a. Occurrences of organophosphorus esters and phthalates in the microplastics from the coastal beaches in north China. Sci. Total Environ. 616-617, 1505-1512. pollution in the surface waters of the Bohai Sea, China. Environ. Pollut. 231, 541-548.

Zhang, Z. M., Zhang, H. H., Zhang, J., Wang, Q. W., Yang, G. P., 2018b. Occurrence, distribution, and ecological risks of phthalate esters in the seawater and sediment of Changjiang River Estuary and its adjacent area. Sci. Total Environ. 619, 93-102.

714 Zhang, Z. M., Zhang, H. H., Zou, Y. W., Yang, G. P., 2018c. Distribution and ecotoxicological state of phthalate esters in the sea-surface microlayer, seawater and sediment of the Bohai Sea and the Yellow Sea. Environ. Pollut. 240, 235-247.

Zhao, S., Zhu, L., Li, D., 2015. Microplastic in three urban estuaries, China. Environ. Pollut. 206, 597-604.

Zhao, S., Zhu, L., Wang, T., Li, D., 2014. Suspended microplastics in the surface water of the Yangtze Estuary System, China: first observations on occurrence, distribution. Mar. Pollu. Bull. 86 (1-2), 562-568.

Zheng, Y., Li, J., Cao, W., Liu, X., Jiang, F., Ding, J., Yin, X., Sun, C., 2019. Distribution characteristics of microplastics in the seawater and sediment: A case study in Jiaozhou Bay, Sea, China: Observations on occurrence, distribution and identification. Sci. Total 
728 Zhu, J.M., Zhang, Q., Li, Y.P., Tan, S.D., Kang, Z.J., Yu, X.Y., Lan, W.L., Cai, L., Wang, J.Z., Shi, H.H., 2019. Microplastic pollution in the Maowei Sea, a typical mariculture bay of

730 China. Sci. Total Environ. 658, 62-68.

731 


\section{Figure Captions}

733 Fig. 1 The geographic location of JZB and sampling stations of surface seawater. The

734 red dots represent water sampling sites, the red pentagram represents the location of

735 Qingdao municipal government, the transparent pentagrams represent the locations of

736 district governments, and the blue rhombuses represent the locations of sewage 737 treatment plants.

738 Fig. 2 The abundance of MPs (a), concentration of $\sum_{6}$ PAEs (b), MPs' polymer risk 739 index H (c) and pollution load index PLI (d) in JZB surface seawater.

740 Fig. 3 Comparison of MPs abundance in JZB surface water with previously reported 741 data.

742 Fig. 4 Proportion of different sizes (a), shapes (b), colors (c), polymer types (d) of 743 MPs from JZB surface seawater at each sampling site.

744 Fig. 5 Identification of typical MPs in JZB surface seawater using $\mu$-FT-IR. Values in 745 brackets indicate the matches of the spectra with the standards. Scale bar of the right 746 of photograph is $100 \mu \mathrm{m}$.

747 Fig. 6 Linear regression of MPs abundance and $\Sigma_{6}$ PAEs observed in JZB surface 748 seawater. 
Fig. 1

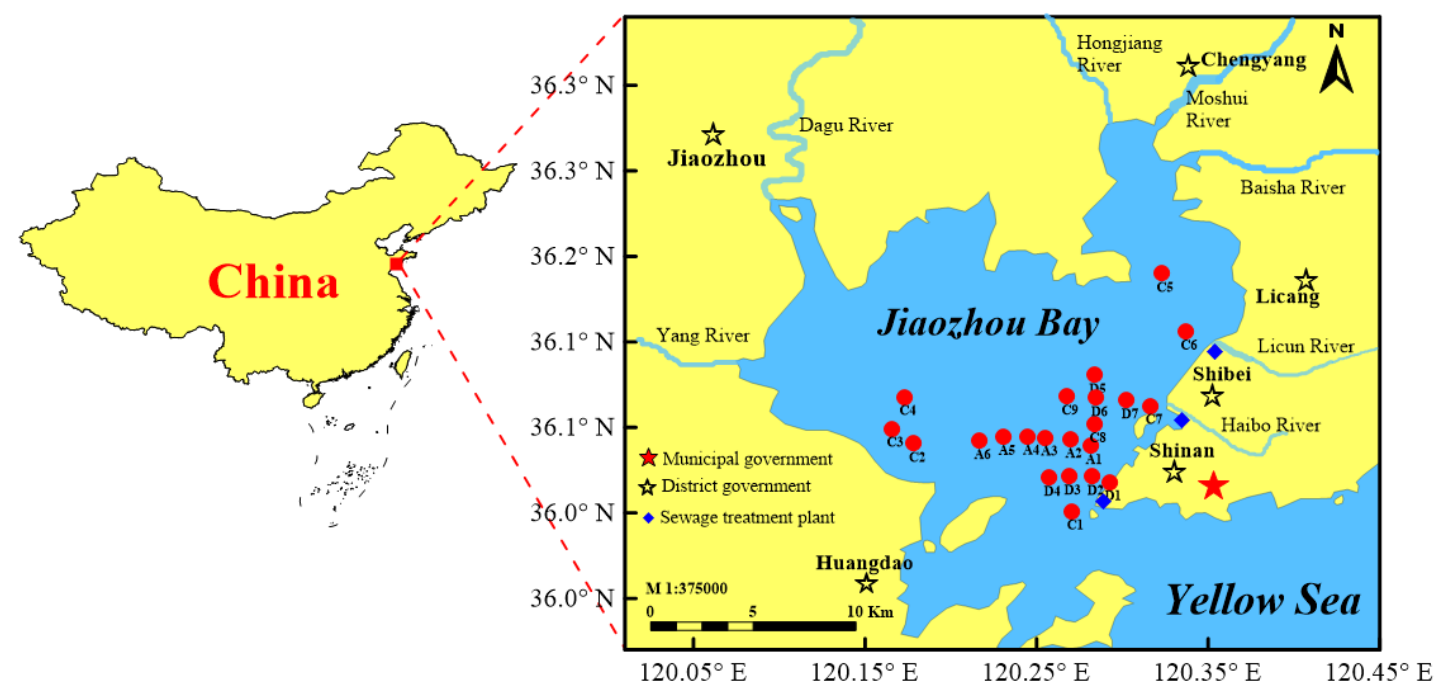

761

762

763

764

765

766

767

768

769

770

771

772

773

774

775

776

777

778

779

780

781

782

783

784

785

786

787

788

789 
Fig. 2

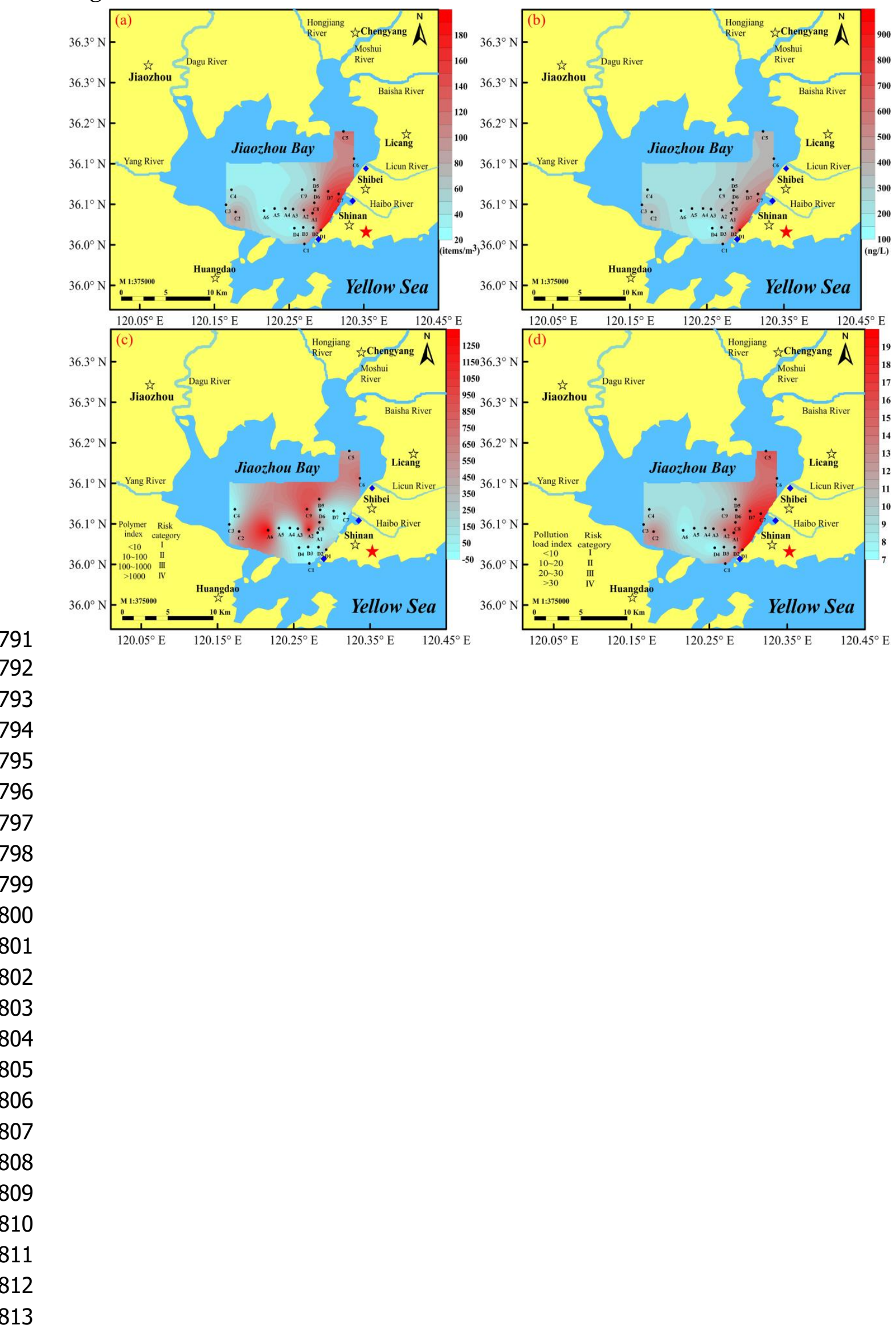


Fig. 3

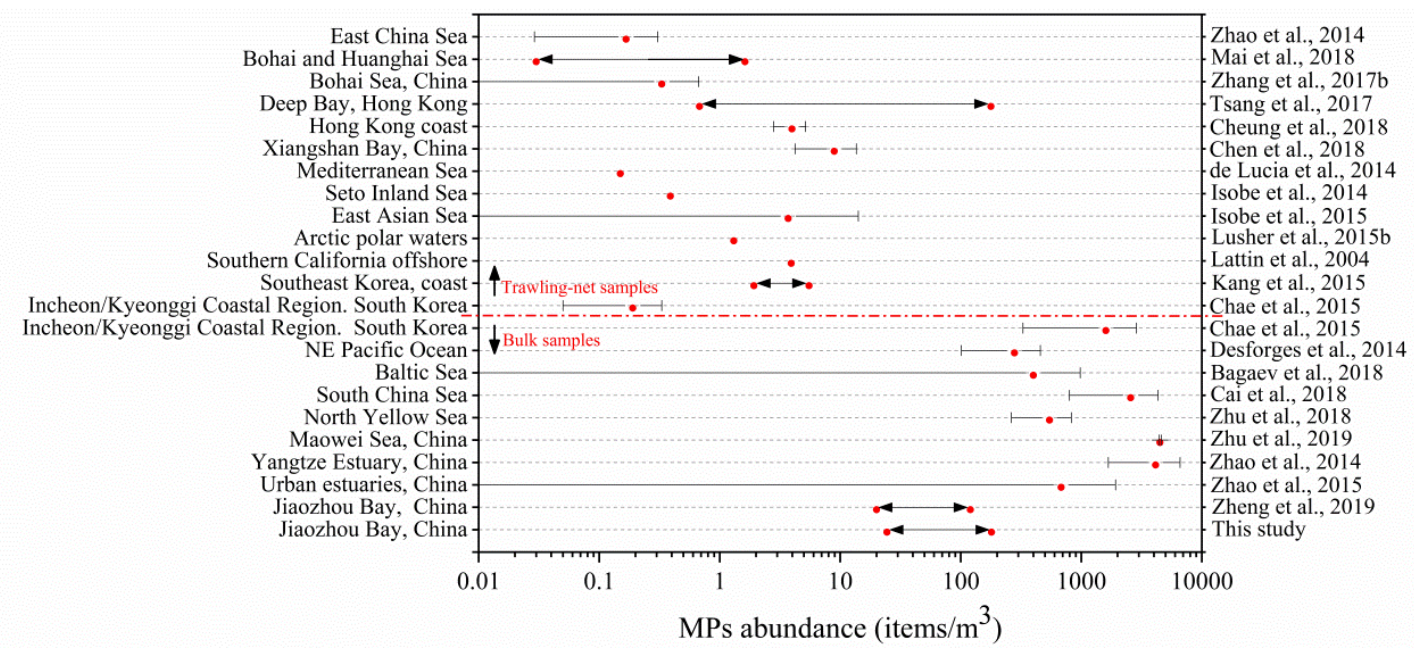

816

817

818

819

820

821

822

823

824

825

826

827

828

829

830

831

832

833

834

835 
Fig. 4
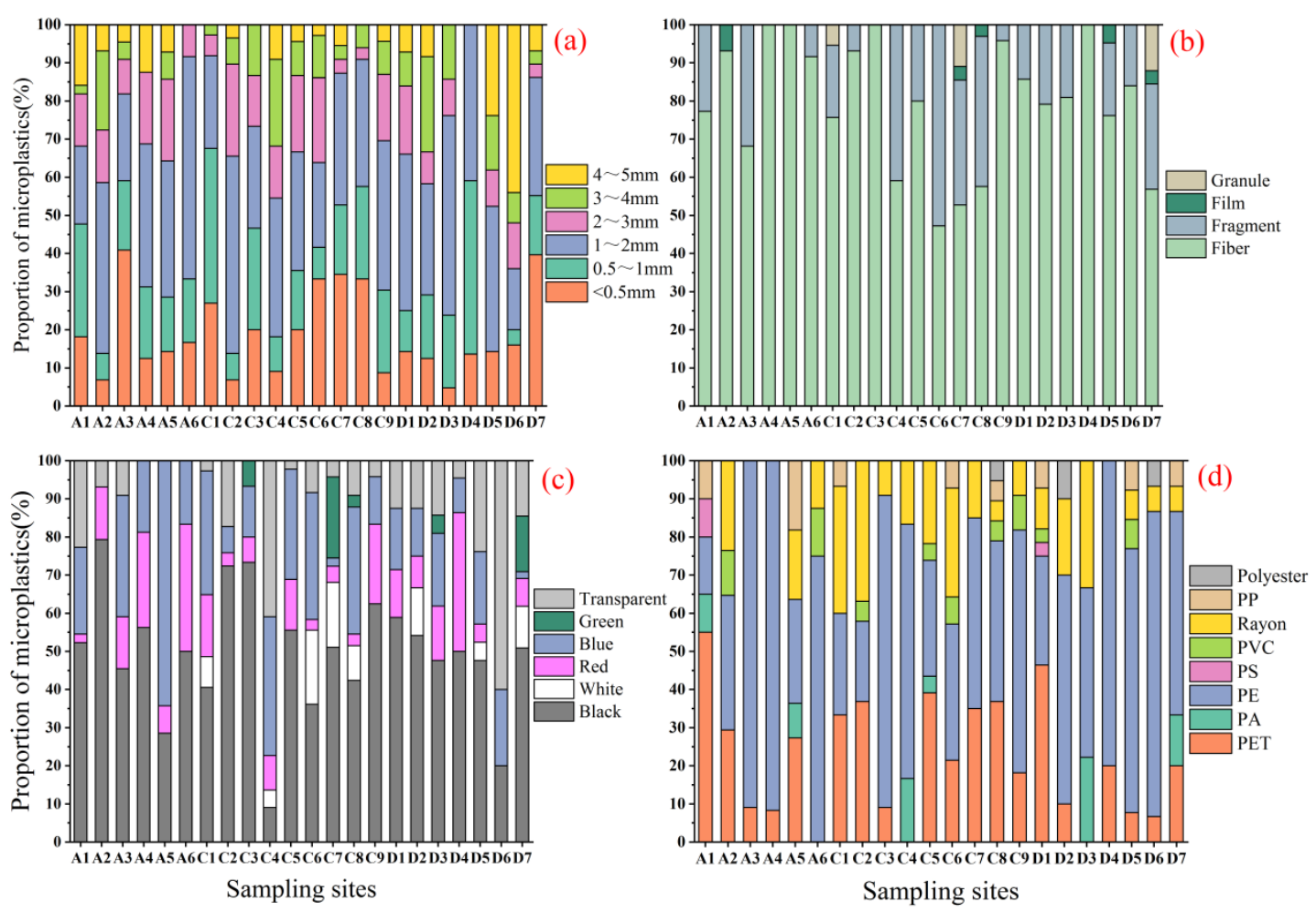
Fig. 5

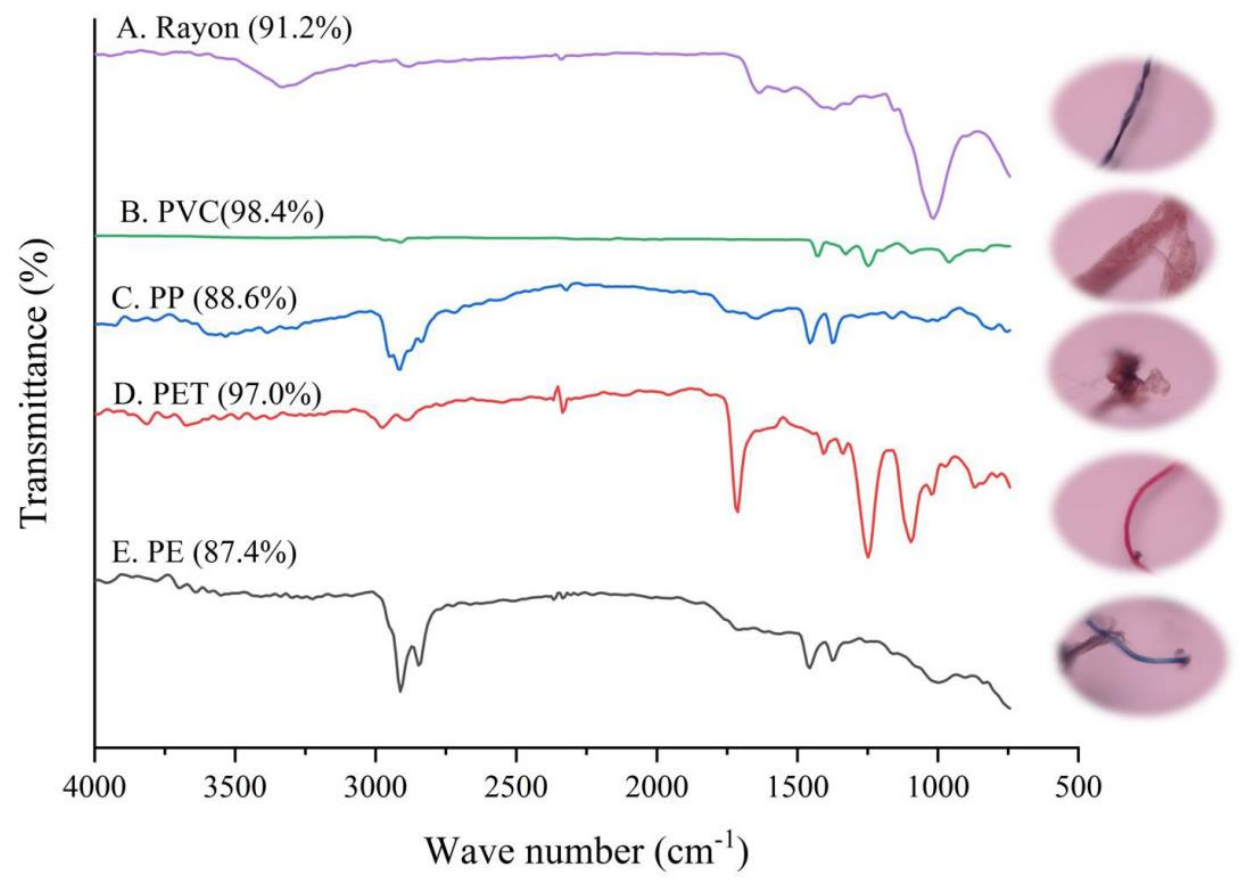

874

875

876

877

878

879

880

881

882

883

884

885

886

887

888

889

890

891

892

893

894

895

896

897

898 
Fig. 6

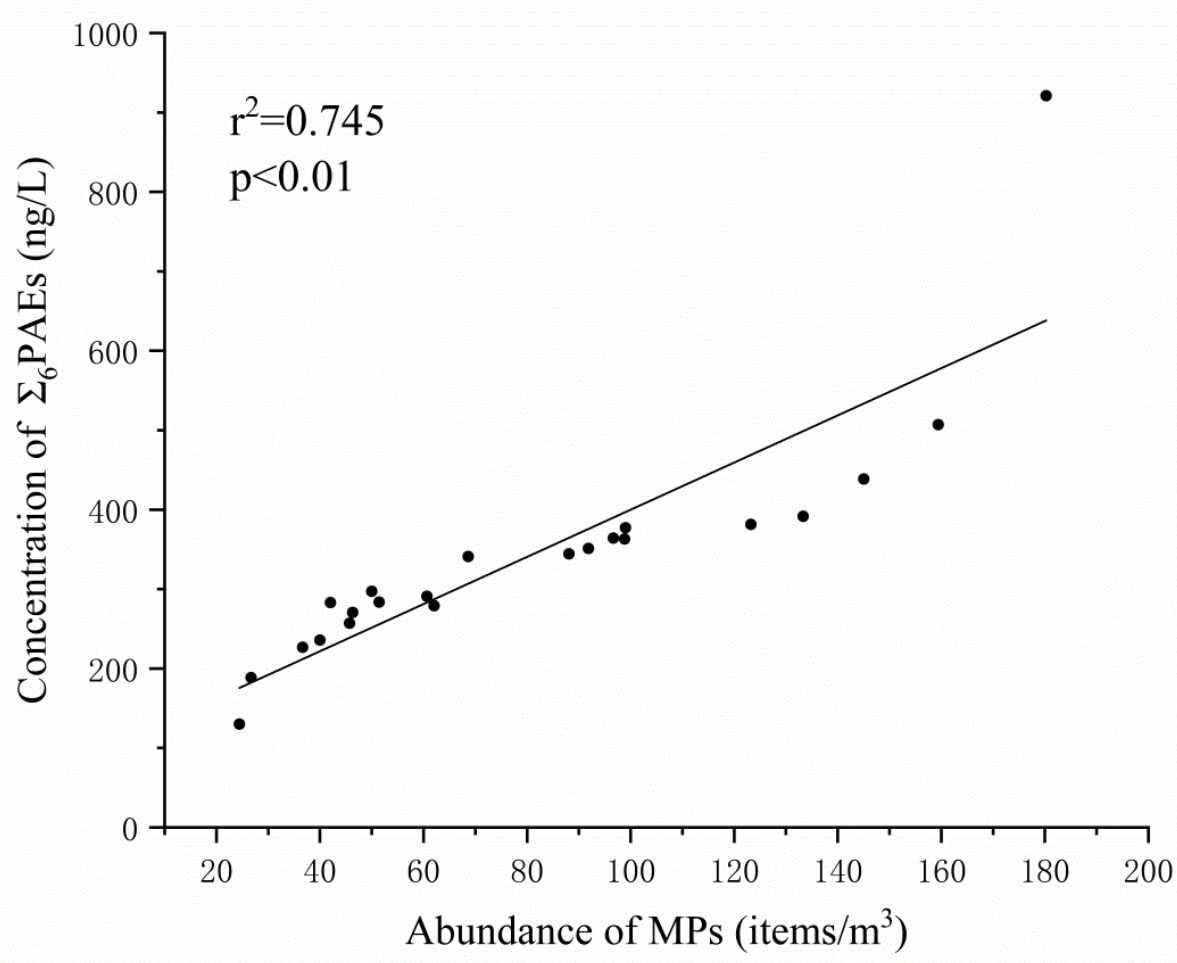

900 